\title{
Erratum to: Acute mechanical overload increases IGF-I and MMP-9 mRNA in 3D tissue-engineered skeletal muscle
}

\author{
D. J. Player • N. R. W. Martin - S. L. Passey • \\ A. P. Sharples $\cdot$ V. Mudera $\cdot$ M. P. Lewis
}

Published online: 25 March 2014

(C) Springer Science+Business Media Dordrecht 2014

\section{Erratum to: Biotechnol Lett \\ DOI 10.1007/s10529-014-1464-y}

Unfortunately, Fig. 5 has been published as an exact copy of Fig. 4, The figure legend is correct, but the published graph for Fig. 5 is not the correct one. The correct Fig. 5 and its legend is provided in this erratum.

The online version of the original article can be found under doi:10.1007/s10529-014-1464-y.

D. J. Player · N. R. W. Martin · S. L. Passey .

A. P. Sharples · M. P. Lewis ( $₫)$

Musculoskeletal Biology Research Group, School of Sport, Exercise and Health Sciences, Loughborough University, Leicestershire LE11 3TU, UK

e-mail: m.p.lewis@lboro.ac.uk

D. J. Player

e-mail: d.player@lboro.ac.uk

\section{S. L. Passey}

Department of Pharmacology, University of Melbourne, Medical Building, Parkville, Melbourne, VIC 3010, Australia
A. P. Sharples
Stem Cells, Ageing and Molecular Physiology (SCAMP) Unit, Research Institute for Sport and Exercise Sciences (RISES), School of Sport and Exercise Sciences, Liverpool John Moores University, Tom Reilly Building, Byrom Street, Liverpool, UK
V. Mudera
Division of Surgery and Interventional Sciences, UCL Institute of Orthopaedics and Musculoskeletal Science, Stanmore, UK 

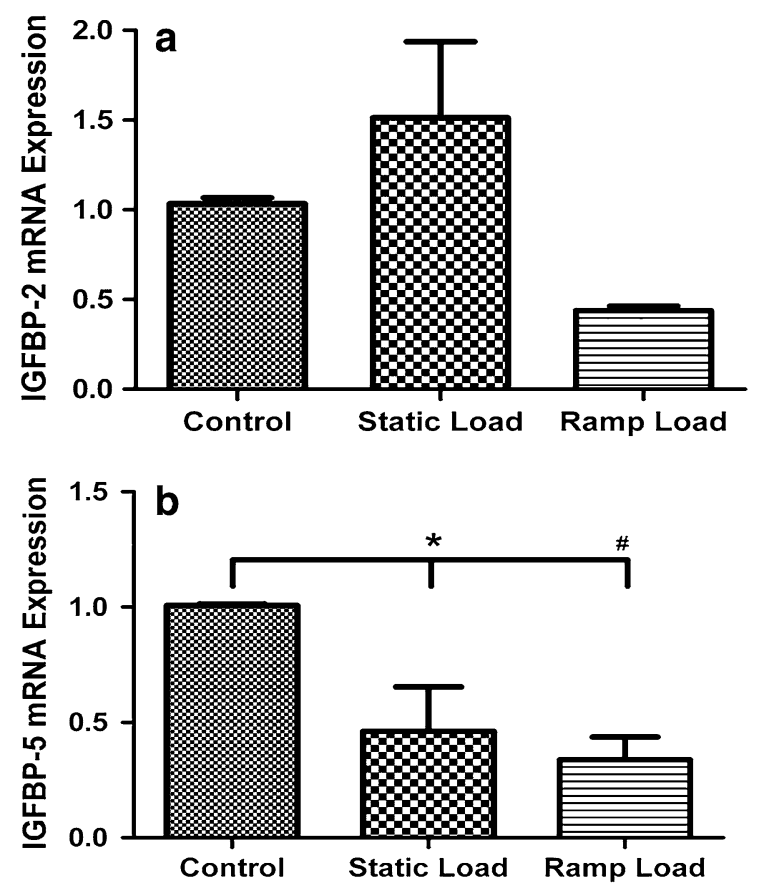

Fig. 5 a Regulation of IGFBP-2 mRNA in the STL condition, with a non-significant reduction in RPL, compared to CON ( $p=0.057$ ). b IGFBP-5 mRNA expression following overload regimes $(p=0.018)$, with significance in the RPL conditioncompared to CON, and approaching significance in STL $\left({ }^{*} p=0.027\right.$ and ${ }^{*} p=0.059$ respectively). No difference in IGFBP-5 mRNA was found between overload conditions $(p=1)$. All data is normalised to the expression of RPIIB and made relative to $N=1 \mathrm{CON}$ construct. $N=3+$ per condition. Bars mean $\pm \mathrm{SD}$ 